\title{
Efficacy of organic acids as an alternative to antibiotic growth promoters in weaned pigs
}

\author{
Tung M. Che ${ }^{1 *}$, Nhan T. M. Nguyen ${ }^{1}$, Hai T. Nguyen ${ }^{1}$, Tai T. Le ${ }^{2}$, \& Alexandre Péron ${ }^{3}$ \\ ${ }^{1}$ Department of Animal Production, Nong Lam University, Ho Chi Minh City, Vietnam \\ ${ }^{2}$ Animal Breeding Center, Long An, Vietnam \\ ${ }^{3}$ Provimi South-East Asia, Singapore
}

\begin{abstract}
ARTICLE INFO
Research Paper

Received: October 09, 2018

Revised: November 01,2018

\section{Keywords}

Antibiotics

Diarrhea

Growth performance

Nursery pigs

Organic acids
\end{abstract}

Accepted: November 15, 2018

\section{${ }^{*}$ Corresponding author}

Che Minh Tung

Email: tung.cheminh@hcmuaf.edu.vn

\section{ABSTRACT}

The objective of the experiment was to compare effects of dietary supplementation of organic acids (ProHacid Advance, PRO) and antibiotics on growth performance, diarrhea incidence, frequency of antibiotic treatment, and E. coli shedding in weaned pigs. A total of 224 crossbred weaned pigs [(Yorkshire x Landrace) x Duroc; 29 days old)] were allotted to 1 of 4 treatments with 7 replicate pens of 8 pigs each according to sex, litter origin and weight in an RCBD. The 4 dietary treatments included (1) basal diet $+50 \mathrm{mg} / \mathrm{kg}$ neomycin and $10 \mathrm{mg} / \mathrm{kg}$ enramycin (positive control, PC), (2) basal diet without antibiotics (negative control, NC), (3) As $2+0.25 \% \mathrm{PRO}$, and (4) As $2+0.5 \%$ PRO. Over a 4-week study, the results showed that there were no differences in the average daily gain and average daily feed intake of pigs among the 4 treatments $(P=0.328)$. However, pigs fed the PC diet (1.642) and $0.25 \%$ PRO-supplemented diet (1.641) had a lower feed to gain ratio $(P<0.05)$ than those fed the NC diet (1.808). The diarrhea incidence of pigs fed the $0.25 \%$ PRO-supplemented diet $(7.36 \%)$ was lower $(P<0.01)$ than that of pigs fed the PC diet (11.61\%), NC diet (16.70\%), and $0.5 \%$ PRO-supplemented diet (10.08\%). The frequency of antibiotic treatment of pigs consuming the $0.25 \% \mathrm{PRO}$-supplemented diet $(4.67 \%)$ was lower $(P<0.01)$ than that of pigs consuming the PC $\operatorname{diet}(7.33 \%), \mathrm{NC} \operatorname{diet}(9.53 \%)$ and $0.5 \% \mathrm{PRO}$-supplemented diet (7.65\%). No differences were found in the number of fecal E. coli among the 4 treatments. In brief, $0.25 \%$ PRO added to a nursery pig diet would be considered a potential alternative to the use of antibiotics in feed, but further research on this aspect is needed.

Cited as: Che, T. M., Nguyen, N. T. M., Nguyen, H. T, Le, T. T., \& Péron, A. (2018). Efficacy of organic acids as an alternative to antibiotic growth promoters in weaned pigs. The Journal of Agriculture and Development 17(6), 8-14.

\section{Introduction}

Weaning is a critical time during which piglets commonly have low feed intake, retarded growth and diarrhea. Organic acids added to diets may provide benefits through maintaining a low gastric $\mathrm{pH}$ that potentially enhance nutrient digestion and reduce pathogen survival. In recent decades, acidifiers have been reported as potential alternatives, among other feed additives, to antibiotics in pig diets (Partanen \& Mroz, 1999; Kim et al., 2005; Kil et al., 2011). Much of this interest arises from increased public awareness and objection to the use of antibiotics as growth promoters in animal diets. Some previous studies have shown favorable effects with dietary or- 
ganic acids in improving growth performance and feed efficiency, but others have found no effects or negative responses (Partanen \& Mroz, 1999; Kil et al., 2011; Che et al., 2012). Hence, an evaluation of the efficacy of acid products under typical Vietnam conditions is needed to guide the use of an acid-related product. This would provide pig producers with more tools to cope with the recent in-feed antibiotic ban in Vietnam. The objective of the experiment was to evaluate effects of organic acids on growth performance, diarrhea incidence, frequency of antibiotic treatment, and E. coli shedding of weaned pigs from 29 to 57 days of age.

\section{Materials and Methods}

\subsection{Experimental design, animals, and hous- ing}

Two hundred and twenty-four crossbred weaned pigs [(Yorkshire x Landrace) x Duroc; 29 days old; $8.44 \pm 1.01 \mathrm{~kg}$ of BW] were randomly allotted to 4 treatments in a randomized complete block design. Pigs were blocked by their initial body weight within sex. Ancestry was equally distributed across treatments. The 4 experimental treatments included (A) basal diet with antibiotics $(50 \mathrm{mg} / \mathrm{kg}$ neomycin and $10 \mathrm{mg} / \mathrm{kg}$ enramycin, positive control, $\mathrm{PC}$ ), (B) basal diet without antibiotics (negative control, NC), (C) basal diet without antibiotics $+0.25 \%$ ProHacid Advance (PRO), and (D) basal diet without antibiotics $+0.5 \%$ PRO. Each pen within a block had the same number of gilts and barrows. There were 8 pigs/pen and 7 replicate pens/treatment. Pigs were housed in an environmentally controlled building. Each pen measured $2.0 \mathrm{~m} \mathrm{x} 2.5$ $\mathrm{m}$ in size with slatted floor and had one nipple waterer.

\subsection{Experimental diets and animal feeding}

The basal diet was formulated to meet or exceed the nutritional requirements of pigs during the experimental period (NRC, 1998). The experimental diets were obtained by adding antibiotics or PRO on top of the basal diet. ProHacid Advance is a blend of organic acids and their salts, consisting of citric acid, fumaric acid, benzoic acid, calcium formate, calcium lactate, and potassium sorbate. It was provided by Provimi Vietnam. Neomycin and enramycin were included in diets at levels of $50 \mathrm{ppm}$ and $10 \mathrm{ppm}$, respectively. The ingredient composition of the basal diet is presented in Table 1. Pigs were fed a onephase feeding program (29-57 d old). Diets were in mash form. Pigs had free access to feed and water throughout the experiment.

Table 1. Ingredient and nutrient composition of the basal diet (as-fed basis)

\begin{tabular}{lc}
\hline Ingredients & Percentage \\
\hline Corn, ground & 56.15 \\
Soybean meal, 46\% & 34.20 \\
Soybean oil & 4.50 \\
MCP (15\% Ca, 23\% P) & 1.40 \\
Limestone, 38\% & 1.50 \\
Salt & 0.30 \\
Mineral premix ${ }^{2}$ & 0.50 \\
Vitamin premix ${ }^{2}$ & 0.50 \\
Antioxidant & 0.10 \\
Zinc oxide & 0.33 \\
Phytase & 0.01 \\
L-Lys, 78.8\% & 0.38 \\
DL-Met, 99\% & 0.08 \\
L-Thr, 98.5\% & 0.05 \\
\hline Nutrient analysis & \\
\hline ME, kcal/kg ${ }^{3}$ & 3400 \\
DM, \% & 89.55 \\
Crude Protein, \% & 20.98 \\
Ether extract, \% & 6.75 \\
Crude fiber, \% & 2.29 \\
Ash, \% & 6.28 \\
Ca, \% & 0.90 \\
Total P, \% & 0.70 \\
\hline
\end{tabular}

${ }^{1}$ Provided per $\mathrm{kg}$ of diet: $\mathrm{Fe}(100 \mathrm{ppm}), \mathrm{Cu}(40 \mathrm{ppm}), \mathrm{Zn}(80$ ppm), Mn (20 ppm), Se (0.3 ppm), I (0.3 ppm).

${ }^{2}$ Provided per $\mathrm{kg}$ of diet: vitamin A (6000 IU), vitamin D3 (600 IU), vitamin E (60 IU), vitamin K (5), vitamin B2 (9 $\mathrm{mg})$, vitamin B5 (27 mg), vitamin B12 (0.05 mg), niacin (50 $\mathrm{mg})$.

${ }^{3}$ Calculated.

\subsection{Feed sample analyses}

A feed sample was ground to pass through a 1$\mathrm{mm}$ screen before analysis and analyzed according to the standard methods. Diet samples were analyzed for DM (EC 152/2009), CP (AOAC 2001.11), crude fat (TCVN 4331:2001), crude fiber (AOCS Ba-6a-05), ash (EC 152/2009), Ca (AAS08, reference 73/46/EEC), and P (AOAC 965.17). The nutrient analyses were performed by Upscience Vietnam in Binh Duong province, Vietnam. The analyzed nutrient composition of the basal diet is presented in Table 1 . 


\subsection{Measurement of pig performance, diar-} rhea incidence, and antibiotic treatment

The initial BW of pigs in each pen was recorded at the commencement of the experiment. The subsequent pen weights and feed disappearance measurements were determined at 57 days of age. The ADG, ADFI, and F:G were calculated on a per-pen basis. Pigs with diarrhea were recorded daily by visual observations with a score from 1 to 5 ( $1=$ normal; $2=$ moist feces; $3=$ mild diarrhea; $4=$ severe diarrhea; $5=$ watery diarrhea). Incidence of diarrhea was calculated by counting pig days with diarrhea score of 3 or greater (pasty and liquid feces) during the entire experimental period. The number of antibiotic treatments per pen was also recorded daily.

\subsection{Bacterial analysis}

Fecal samples were directly collected by a fecal loop from one identified pig per pen at 29 days of age for enumeration of E. coli., and subsequent samples were taken from the same pigs in each pen at 43 and 57 days of age. Fecal samples were placed on ice for transportation to the lab, where analysis was immediately done. A 10-g sample of feces was added to $90 \mathrm{~mL}$ of buffered peptone broth, homogenized, and then serially diluted by ten-fold. From all five consecutive dilutions (from $10^{-1}$ to $10^{-5}$ ), $1 \mathrm{~mL}$ was inoculated into each 3 lauryl sulfate broth (LSB) media and incubated at $37^{0} \mathrm{C}$ for 24 to $48 \mathrm{~h}$. Gas positive tubes of 3 consecutive dilutions were transferred into $E$. coli medium (EC) and incubated at $44.5^{\circ} \mathrm{C}$ for 24 $\mathrm{h}$. The EC positive tubes were used to inoculate eosin methylene blue (EMB) agar plates and incubated for $24 \mathrm{~h}$ at $37^{\circ} \mathrm{C}$ for E. coli isolation. Finally, presumptive $E$. coli colonies from the EMB agar plates were confirmed by the IMViC test. Positive tubes of three consecutive tubes were used for standard MPN calculation. The number of $E$. coli is expressed as $\log _{10}$ MPN per one gram of fecal sample.

\subsection{Statistical Analysis}

Data were analyzed as an RCBD using the GLM procedure (SAS Inst. Inc., Cary, NC). The pen was considered the experimental unit for ADFI, BW, ADG, and FCR, whereas individual pig was considered the experimental unit for the other parameters. When a significant $F$ value for treatment means was observed in analysis of variance, the treatment means were compared using Tukey's test. The incidence of diarrhea and frequency of medical treatments were compared by Chi-square test. Treatment effects were considered significant at $P<0.05$.

\section{Results}

\subsection{Growth performance}

At the commencement of the experiment (29 days of age), there were no differences ( $P=$ $0.471)$ in the initial BW of pigs among the treatments (Table 2). At the end of the experiment (57 days of age), although pigs fed the diet containing $0.25 \%$ PRO $(17.65 \mathrm{~kg} / \mathrm{pig})$ had greater $\mathrm{BW}$ than those fed the PC diet $(17.48 \mathrm{~kg} / \mathrm{pig}), \mathrm{NC}$ diet $(16.78 \mathrm{~kg} / \mathrm{pig})$, and $0.5 \%$ PRO-supplemented diet $(17.40 \mathrm{~kg} / \mathrm{pig})$, these differences were not statistically significant $(P=0.286)$. There were no differences in ADFI and ADG of pigs among the 4 treatments $(P>0.05)$. However, there were significant differences in F:G ratios of pigs among the 4 treatments $(P=0.021)$. Particularly, pigs fed the PC diet (1.642) and $0.25 \%$ PRO-supplemented diet (1.641) had a lower F:G ratio $(P<0.05)$ than those fed the NC diet (1.808).

\subsection{Diarrhea incidence and medical treatment}

There were significant differences in the diarrhea incidence of pigs among the 4 treatments $(P<0.001$; Figure 1$)$. Pigs fed the $0.25 \%$ PROsupplemented diet $(7.30 \%)$ had a lower rate of diarrhea $(P<0.01)$ than those fed the PC diet (11.61\%), NC diet (16.70\%) and 0.5\% PROsupplemented diet $(10.08 \%)$. The diarrhea incidence of pigs fed the $\mathrm{NC}$ diet was greater $(P$ $<0.001)$ than that of pigs fed the PC diet and $0.5 \%$ PRO-supplemented diet. No difference $(P=$ 0.168 ) in the incidence of diarrhea was found between the PC diet and 0.5\% PRO-supplemented diet.

There were significant differences in the frequency of antibiotic treatments among the 4 treatments $(P<0.001$; Figure 2$)$. Pigs fed the $0.25 \%$ PRO-supplemented diet $(4.67 \%)$ had a lower frequency of antibiotic treatments $(P<$ $0.01)$ than those fed the PC $\operatorname{diet}(7.33 \%)$, NC diet $(9.53 \%)$ and $0.5 \%$ PRO-supplemented diet $(7.65 \%)$. The frequency of antibiotic treatments 
Table 2. Effects of dietary supplementation of organic acids on growth performance of nursery pigs

\begin{tabular}{|c|c|c|c|c|c|c|}
\hline \multirow{2}{*}{ Item } & \multicolumn{4}{|c|}{ Dietary treatments ${ }^{1}$} & \multirow{2}{*}{ SEM } & \multirow{2}{*}{$P$} \\
\hline & $\begin{array}{l}\text { Positive } \\
\text { control }\end{array}$ & $\begin{array}{l}\text { Negative } \\
\text { control }\end{array}$ & $\begin{array}{c}0.25 \% \text { ProHacid } \\
\text { Advance }\end{array}$ & $\begin{array}{c}0.5 \% \text { ProHacid } \\
\text { Advance }\end{array}$ & & \\
\hline Initial BW, kg/pig & 8.45 & 8.45 & 8.44 & 8.41 & 0.05 & 0.909 \\
\hline Final BW, kg/pig & 17.48 & 16.78 & 17.65 & 17.40 & 0.33 & 0.286 \\
\hline ADFI, $\mathrm{g}$ & 530.3 & 524.2 & 533.1 & 528.6 & 18.46 & 0.989 \\
\hline ADG, $\mathrm{g}$ & 322.6 & 293.5 & 325.3 & 321.2 & 12.91 & 0.297 \\
\hline $\mathrm{F}: \mathrm{G}, \mathrm{kg} / \mathrm{kg}$ & $1.642^{\mathrm{b}}$ & $1.808^{\mathrm{a}}$ & $1.641^{\mathrm{b}}$ & $1.657^{\mathrm{ab}}$ & 0.040 & 0.021 \\
\hline
\end{tabular}

${ }^{1} 7$ pens/treatment and 8 pigs/pen.

a-b Means with different superscript letters within a row differ $(P<0.05)$.

Table 3. Effects of dietary supplementation of organic acids on fecal shedding of E. coli $\left(\log _{10} \mathrm{MPN} / \mathrm{g}\right)$

\begin{tabular}{|c|c|c|c|c|c|c|}
\hline \multirow{2}{*}{ Age, d } & \multicolumn{4}{|c|}{ Dietary treatments ${ }^{1}$} & \multirow{2}{*}{ SEM } & \multirow{2}{*}{$P$} \\
\hline & $\begin{array}{c}\text { Positive } \\
\text { control }\end{array}$ & $\begin{array}{c}\text { Negative } \\
\text { control }\end{array}$ & $\begin{array}{c}0.25 \% \text { ProHacid } \\
\text { Advance }\end{array}$ & $\begin{array}{c}0.5 \% \text { ProHacid } \\
\text { Advance }\end{array}$ & & \\
\hline 29 & 6.01 & 5.82 & 6.06 & 6.42 & 0.391 & 0.744 \\
\hline 43 & 5.60 & 5.52 & 5.77 & 4.59 & 0.424 & 0.230 \\
\hline 57 & 5.44 & 5.55 & 5.76 & 6.55 & 0.745 & 0.050 \\
\hline
\end{tabular}

${ }^{1} \mathrm{n}=7$ (7 pigs/treatment).

of pigs fed the NC diet was greater $(P=0.027)$ than that of pigs fed the $\mathrm{PC}$ diet but was not different $(P=0.061)$ from that of pigs fed the $0.5 \%$ PRO-supplemented diet. No difference $(P$ $=0.735)$ in the frequency of antibiotic treatments was found between the PC diet and 0.5\% PROsupplemented diet.

\subsection{Fecal E. coli concentration}

No effects of dietary treatments on $E$. coli shedding were found at 29 days of age $(P=0.744$; Table 3). At 43 days of age, there were no differences in the $E$. coli counts among the 4 treatments $(P=0.230)$. At the end of the experiment ( $57 \mathrm{~d}$ old), the $E$. coli counts in pigs receiving the $0.5 \%$ PRO-supplemented diet (6.55 $\log _{10}$ $\mathrm{MPN} / \mathrm{g})$ tended $(P=0.050)$ to be greater than those in pigs fed the $\mathrm{PC} \operatorname{diet}\left(5.44 \log _{10} \mathrm{MPN} / \mathrm{g}\right)$, $\mathrm{NC} \operatorname{diet}\left(5.55 \log _{10} \mathrm{MPN} / \mathrm{g}\right)$, and $0.25 \% \mathrm{PRO}-$ supplemented diet $\left(5.76 \log _{10} \mathrm{MPN} / \mathrm{g}\right)$.

\section{Discussion}

For decades, antibiotics have been used in food animal production for disease prevention and growth promotion. However, in recent years, the use of antibiotics as growth promoters has declined due to an increasing concern about antimicrobial resistance in bacteria. Vietnam has recently banned the use of antibiotics as growth promoters in animal feeds, but some antibiotics such as neomycin and enramycin can be used at low doses. In the current study, organic acids added to the nursery diets had the same weight gain as those fed the PC diet and numerically increased the weight gain of pigs by over $9 \%$ as compared with the NC diet. Indeed, it was reported that effects of organic acids on growth rate of weaned pigs were inconsistent. Some researchers have shown positive effects with dietary supplementation of organic acids in improving growth rate (Bergstrom et al., 1996; Boling et al., 2000), but others have found nothing or negative responses (Radecki et al., 1988; Manzanilla et al., 2004; Che et al., 2012). The efficacy of organic acids on growth performance may be dependent on several factors such as complexity of diet, type of acid, inclusion level of acid, etc. For example, addition of $0.3 \%$ benzoic acid to a nursery diet did not clearly affect weight gain of pigs (Phan et al., 2014), but a diet supplemented with 0.5$1.0 \%$ benzoic acid improved growth rate of pigs (Kluge et al., 2006; Guggenbuhl et al., 2007).

Organic acids added to a diet have been shown to produce beneficial effects through reduced survival of pathogens and increased digestion of nutrients leading to better animal health and performance (Partanen, 2001; Lawlor et al., 2006; Kil et al., 2011). Especially, under stressful or dis- 


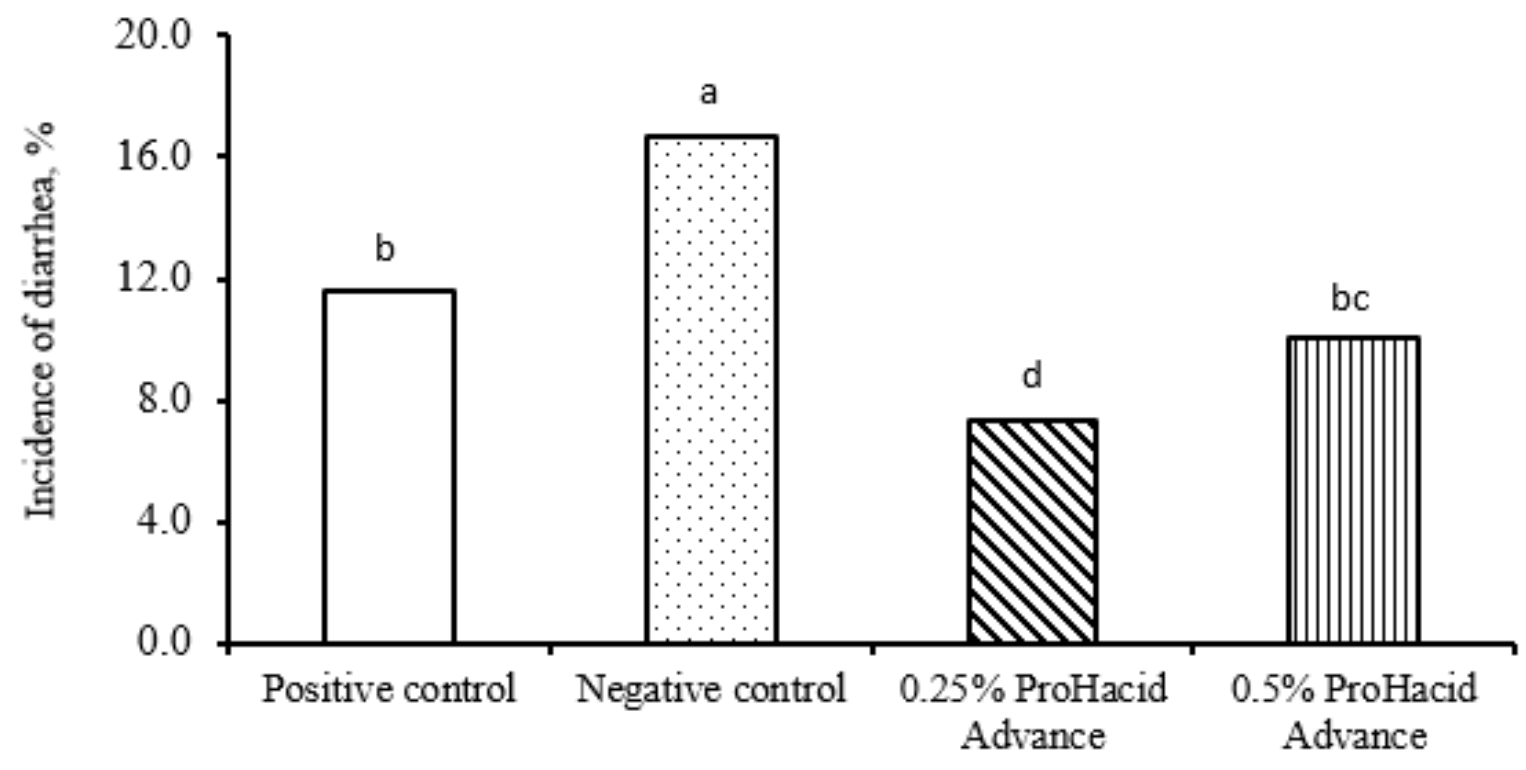

Figure 1. Effects of ProHacid Advance on the incidence of diarrhea during the experimental period. There were 56 pigs/treatment. Diarrhea incidence: Diarrhea x 100/pig days; Diarrhea: number of pig days with diarrhea; Pig days: number of pigs $\mathrm{x}$ the number of days of diarrhea observation. ${ }^{\text {a-d }}$ Means with different superscript letters differ $(P<0.05)$.

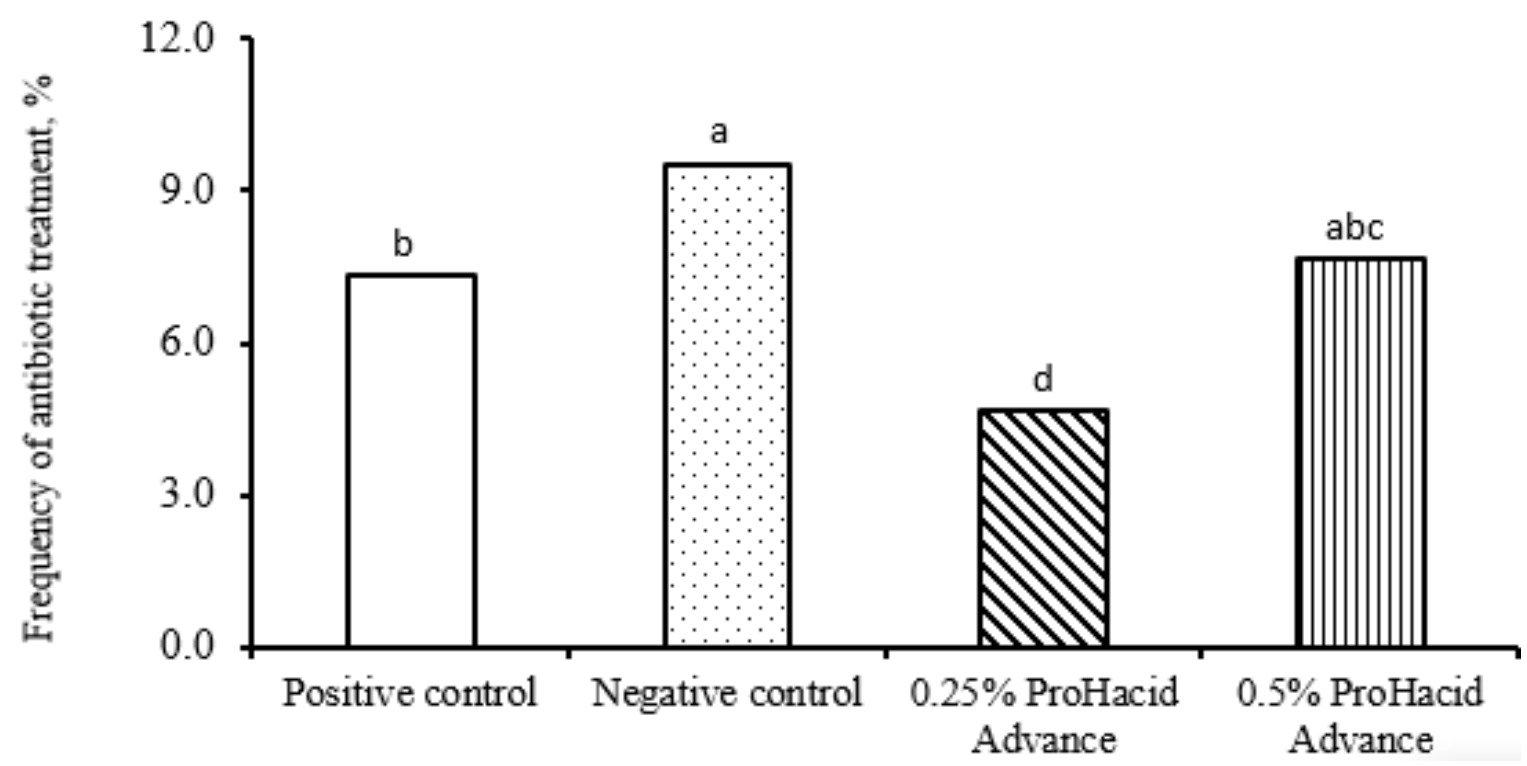

Figure 2. Effects of dietary supplementation of ProHacid Advance on the frequency of antibiotic treatment during the experimental period. There were 56 pigs/treatment. Frequency of antibiotic treatment: Medical treatment x 100/pig days; Medical treatment: number of pig days with treatment; Pig days: number of pigs $\mathrm{x}$ the number of days of medical treatment observation. ${ }^{\mathrm{a}-\mathrm{d}}$ Means with different superscript letters differ $(P$ $<0.05)$. 
ease challenge conditions, organic acids may be a useful tool to reduce unfavorable impacts such as increased diarrhea and high mortality (Risley et al., 1993; Tsiloyiannis et al., 2001; Manzanilla et al., 2004). First, it should be noted that although there were no clear effects of organic acids on weight gain of pigs, $0.25 \%$ PRO added to the diet significantly improved the feed efficiency of pigs as compared with the NC diet (Table 2). This improvement is likely associated with the ability of organic acids in lowering gastrointestinal $\mathrm{pH}$, thereby increasing nutrient digestibility (Ravindran \& Kornegay, 1993; Partanen \& Mroz, 1999; Partanen, 2001). In a metaanalysis of organic acids for pigs, Che \& Quach (2011) reported that organic acids added to a nursery diet significantly improved the dry matter and crude protein digestibilities. In the current study, pigs fed the diet containing antibiotics (neomycin \& enramycin) had the same FCR as those fed PRO-supplemented diets. In addition, feeding the $0.25 \%$ PRO-supplemented diet to pigs reduced the incidence of diarrhea compared to feeding the other diets. This improvement may be associated with the organic acids-enhanced feed efficiency which would help limit the substrates, especially protein for bacterial fermentation. In cecum and colon, it was reported that undigested proteins produced toxic compounds causing diarrhea in pigs (Makkink, 2001).

Dietary supplementation of PRO did not clearly influence the $E$. coli shedding of pigs (Table 3 ). These results agree with those of previous studies. Walsh et al. (2007) reported that pigs fed a blend of organic acids had the same $E$. coli shedding as those fed the control. According to Phan et al. (2014), 0.3\% benzoic acid added to nursery diets did not affect the number of fecal $E$. coli. In the intestines, the balance of harmful and beneficial microbes is likely more important than the dominance of certain bacterial strain. This helps maintain a balanced microflora system leading to more healthy gut and less diarrhea. It has been shown that organic acids differently affect the microflora populations along the gastrointestinal tract, and they do not produce an environment that is favorable for potentially beneficial bacteria but harmful to coliforms and E. coli (Che \& Quach, 2011). As shown in Table 3 , pigs fed $0.5 \%$ PRO-supplemented diet had a numerically greater number of fecal $E$. coli than those fed the other diets at 56 days of age.

\section{Conclusions}

ProHacid Advance added to a nursery diet at an inclusion level of $0.25 \%$ improved the feed efficiency of pigs as compared with the negative control. There were no differences in growth rate and feed efficiency between pigs fed ProHacid Advance and antibiotics. The addition of $0.25 \%$ ProHacid Advance reduced the diarrhea incidence and frequency of medical treatment of pigs as compared with the positive and negative controls. Thus, ProHacid Advance would be considered a potential alternative to the use of antibiotics in nursery pig diets, but further research on this aspect is needed.

\section{Conflicts of interest}

The authors declare no conflicts of interest.

\section{References}

Bergstrom, J. R., Nelssen, J. L., Tokach, M. D., Goodband, R. D., Loughmiller, J. A., Musser, R. E., \& Nessmith, W. B. Jr. (1996). An evaluation of several diet acidifers com-monly used in pig starter diets to improve growth performance. Kansas Agricultural Experiment Station Progress Report 0(10), 74-77.

Boling, S. D., Webel D. M., Mavromichalis I., Parsons C. M., \& Baker, D. H. (2000). The effects of citric acid on phytate-phosphorus utilization in young chicks and pigs. Journal of Animal Science 78(3), 682-689.

Che, T. M., Adeola, O., Azain, M. J., Carter, S. D., Cromwell, G. L., Hill, G. M., Mahan, D. C., Miller, P. S., \& Pettigrew, J. E. (2012). Effect of dietary acids on growth performance of nursery pigs: A cooperative study. Journal of Animal Science 90(12), 4408-4413.

Che, T. M., \& Quach, A. T. (2011). A critical review of acidifiers in pig diets part 1: Proposed mechanisms of action of acids. Journal of Animal Husbandry Sciences and Technics 8(149), 8-17.

Guggenbuhl, P., Séon A., Quintana A. P., \& Nunes, C. S. (2007). Effects of dietary supplementation with benzoic acid on the zootechnical performance, the gastrointestinal microflora and the ileal digestibility of the young pig. Livestock Science 108(1-3), 218-221.

Kil, D. Y., Kwon, W. B., \& Kim, B. G. (2011). Dietary acidifiers in weanling pig diets: a review. Revista Colombiana de Ciencias Pecuaris 24(3), 231-247.

Kim, Y. Y., Kil, D. Y., Oh, H. K., \& Han., I. K. (2005). Acidifier as an alternative material to antibiotics in animal feed. Asian-Australasian Journal of Animal Sciences 18(7), 1048-1060.

Kluge, H., Broz J., \& Eder K. (2006). Effect of benzoic acid on growth performance, nutrient digestibility, nitrogen balance, gastrointestinal microflora and parameters of microbial metabolism in piglets. Journal of 
Animal Physiology and Animal Nutrition 90(7), 316324.

Lawlor, P. G., Lynch, P. B., \& Caffrey, P. J. (2006). Effect of fumaric acid, calcium formate and mineral levels in diets on the intake and growth performance of newly weaned pigs. Irish Journal of Agricultural Food Research 45(1), 61-71.

Makkink, C. (2001). Acid binding capacity in feedstuffs. Feed International 22(10), 24-27.

Manzanilla, E. G., Perez, J. F., Martin, M., Kamel, C., Baucells, F., \& Gasa, J. (2004). Effect of plant extracts and formic acid on the intestinal equilibrium of earlyweaned pigs. Journal of Animal Science 82(11), 32103218.

NRC (National Research Council). (1998). Nutrient Requirements of Swine (10 ${ }^{\text {th }}$ ed.). Washington DC, USA: National Academy Press.

Partanen, K. (2001). Organic acids - their efficacy and modes of action in pigs. In Piva, A., Bach Knudsen, K. E., and Linndberg, J. E. (Eds). Gut Environment of Pigs (201-218). Nottingham, UK: Nottingham University Press.

Partanen, K., \& Mroz, Z. (1999). Organic acids for performance enhancement in pig diets. Nutrition Research Reviews 12(1), 117-145.

Phan, Q. N., Dong, D. D., Nguyen, H. N, \& Che, T. M. (2014). Effects of benzoic acid and dietary acid binding capacity on growth performance and health of weaned pigs. Nong Lam University Journal of Agricultural Sciences and Technology 1, 41-48.
Radecki, S. V., Juhl, M. R., \& Miller, E. R. (1988). Fumaric and citric acids as feed additives in starter pig diets: Effect on performance and nutrient balance. Journal of Animal Science 66(10), 2598-2605.

Ravindran, V., \& Kornegay, E. T. (1993). Acidification of weaner pig diets: A review. Journal of the Science of Food and Agriculture 62(4), 313-322.

Risley, C. R., Kornegay, E. T., Lindemann, M. D., Wood, C. M., \& Eigel, W. N. (1993). Effect of feeding organic acids on gastrointestinal digesta measurements at various times postweaning in pigs challenged with enterotoxigenic Escherichia coli. Canadian Journal of Animal Science 73(4), 931-940.

Tsiloyiannis, V. K., Kyriakis, S. C., Vlemmas, J., \& Sarris, K. (2001). The effect of organic acids on the control of porcine post-weaning diarrhoea. Research in Veterinary Science 70(3), 287-293.

Walsh, M. C., Sholly, D. M., Hinson, R. B., Saddoris, K. L., Sutton, A. L., Radcliffe, J. S., Odgaard, R., Murphy, J., \& Richert, B. T. (2007). Effects of water and diet acidification with and without antibiotics on weanling pig growth ang microbial shedding. Journal of Animal Science 85(7), 1799-1808. 